\title{
Management of subdural intracranial empyemas should not always require surgery
}

\author{
D LEYS, A DESTEE, H PETIT, P WAROT \\ From the Department of Neurology, University of Lille, Lille, France
}

SUMMARY Seven patients with subdural empyema were initially treated by antibiotics without surgery. Six have recovered without sequelae. One required delayed surgery and has recovered with epilepsy. The authors emphasise the use of CT for the diagnosis and follow-up of subdural empyema, the principles and modalities of non-surgical treatment, and the good results, especially for late morbidity.

From the medical literature, it is evident that, even when antibiotics became available, most authors have agreed there is need for surgery in all intracranial subdural empyemas. ${ }^{1-3}$ However, this treatment has not prevented serious mortality ${ }^{14}$ and sequelaes. ${ }^{15}$ Since the use of CT for the diagnosis of various central nervous system suppurations, ${ }^{67}$ some authors have treated brain abscesses, ${ }^{6-10}$ extradural/intracranial abscesses $^{11}$ and even spinal epidural abscesses ${ }^{7}$ without surgery. We report here the results obtained with 7 patients with subdural empyema treated without surgery.

\section{Case reports}

The first three patients have been the subject of a previous report in a review about clinical and radiological findings in subdural empyemas. The second patient's history is reported in detail, and the six others are summarised in the table. Each patient's CT scan, before and after treatment, is shown in the figs 1-5.

\section{Patient 2}

This 19-year-old woman had a 1 week history of fever and bifrontal headache and received each day amoxicilline $(1 \mathrm{~g}$ orally) for 4 days. She was admitted to the neurological department on 13 April 1982 with fever $\left(38^{\circ} 5\right)$, headache and vomiting. She was lethargic, with a left hemiplegia and a palsy of both external recti. Her neck was stiff. Generalized seizures occurred. CSF contained 900 white cells $/ \mathrm{mm}^{3}$ ( $100 \%$ polymorphonuclear), protein $0.6 \mathrm{mg} / 1$ and glucose $0.6 \mathrm{~g} / \mathrm{l}$. ESR was $120 \mathrm{~mm} / \mathrm{h}$ and WBC count was 15000 ( $80 \%$ polymorphonuclear). CT (fig $2 a$ ) revealed an interhemispheric area of low density with an enhanced thin

Address for reprint requests: Pr P Warot, MD, Department of Neurology A, Hospital B, 2 avenue Oscar Lambret, F 59037 Lille Cédex, France.

Received 12 April 1985 and in revised form 18 September 1985. Accepted 21 September 1985. margin after contrast and compression of cerebral and ventricular structures. No causative organism was isolated from CSF or blood cultures. Skull radiographs showed opacification of the right maxillary and frontal sinuses. The patient was treated by ampicillin ( $12 \mathrm{~g} \mathrm{IV})$, sisomicine (150 mg IM) and trimethoprim-sulfamethoxazole (320 $\mathrm{mg}-1600 \mathrm{mg}$ IV) for 6 weeks, then by oral amoxicillin $6 \mathrm{~g}$ daily for 4 months. Clonazepam ( $3 \mathrm{mg} \mathrm{IV}$ ) was added during the first $\mathbf{4 8}$ hours and mannitol during the first 5 days. When the treatment was stopped, she had no neurological deficit and CT scan (fig 2b) showed no abnormalities. Thirty months later, she had had no seizure, and did not receive anticonvulsant medication.

\section{Discussion}

The use of CT for diagnosis and follow-up

As in brain abscesses, ${ }^{6}$ a non-surgical treatment of subdural empyemas is possible only if CT can be performed. It reveals small empyemas which could not be diagnosed otherwise, as in the second case reported by Rosazza: ${ }^{13}$ this was a patient with purulent meningitis and without any focal deficit, in whom CT showed a small subdural empyema. CT also allows easy and atraumatic follow-up. ${ }^{214}$

\section{The classical treatment of subdural empyemas}

For most authors, surgery is always required in all subdural empyemas: they often prefer a large craniotomy ${ }^{131516}$ to burr holes, so as to provide purulent material and allow an irrigation of the subdural space with antibiotics. ${ }^{16}$ For these authors, the surgical treatment must be performed in emergency, but Pimontel-Appel ${ }^{14}$ prefers to wait for an improvement of the neurological state, 24 to 48 hours after the onset of antibiotic therapy. In spite of the possibility of improvement with surgical treatment, the importance of antibiotics cannot be neglected.

The first successfully treated cases occurred only 
Table Cases of non-surgically treated subdural empyemas

\begin{tabular}{|c|c|c|c|c|c|c|c|c|c|c|}
\hline \multirow{2}{*}{$\begin{array}{l}\text { Authors } \\
\text { Rasazza }^{13}\end{array}$} & \multicolumn{2}{|c|}{$\begin{array}{l}\text { Sex and } \\
\text { age } \\
\text { (yr) }\end{array}$} & \multirow{2}{*}{$\begin{array}{l}\text { Clinical signs } \\
\text { fever } \\
\text { headache } \\
\text { left hemiplegia }\end{array}$} & \multicolumn{3}{|l|}{$C S F$} & \multirow{2}{*}{$\begin{array}{l}\text { ESR } \mathrm{mm} / \mathrm{h} \\
?\end{array}$} & \multirow{2}{*}{$\begin{array}{l}W B C / \mathrm{mm}^{3} \\
17400\end{array}$} & \multirow{2}{*}{$\begin{array}{l}C T \text { scan } \\
\text { IH SDE }\end{array}$} & \multirow{2}{*}{ 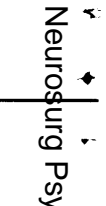 } \\
\hline & $\mathbf{M}$ & 14 & & 33 & 1200 & 720 & & & & \\
\hline Rasazza $^{13}$ & $\mathbf{M}$ & 11 & \multirow{3}{*}{$\begin{array}{l}\text { fever } \\
\text { meningism } \\
\text { fever } \\
\text { meningism } \\
\text { left hemiplegia } \\
\text { fever } \\
\text { focal seizures } \\
\text { generalised status } \\
\text { with coma right } \\
\text { hemiplegia and aphasia } \\
\text { fever } \\
\text { generalised seizures } \\
\text { left hemiplegia } \\
\text { VI palsy meningism } \\
\text { fever } \\
\text { focal seizures } \\
\text { coma } \\
\text { right hemiplegia }\end{array}$} & 316 & 1500 & 721 & $?$ & 17300 & IH SDE & $\stackrel{\text { }}{\stackrel{\rho}{D}}$ \\
\hline $\begin{array}{l}\text { Case } 1 \\
\quad 802284\end{array}$ & $\mathbf{M}$ & 29 & & 830 & 800 & 500 & 26 & 11600 & $\begin{array}{l}\text { IH SDE } \\
\text { left PA } \\
\text { SDE } \\
\text { (fig 1) }\end{array}$ & 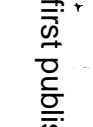 \\
\hline $\begin{array}{l}\text { Case } 2 \\
820869\end{array}$ & $\mathbf{F}$ & 19 & & 900 & 600 & 600 & 120 & 15000 & $\begin{array}{l}\text { IH SDE } \\
\text { (fig 2) }\end{array}$ & 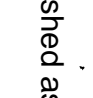 \\
\hline $\begin{array}{l}\text { Case } 4 \\
830286\end{array}$ & $\mathbf{M}$ & 40 & $\begin{array}{l}\text { fever } \\
\text { generalised seizures } \\
\text { right hemiplegia } \\
\text { meningism }\end{array}$ & 5 & 400 & 800 & 60 & 13000 & $\begin{array}{l}\text { FR SDE } \\
\text { (fig 4) }\end{array}$ & $\begin{array}{l}\frac{\omega}{\widehat{D}} \\
\frac{2}{2}\end{array}$ \\
\hline $\begin{array}{l}\text { Case } 5 \\
831075\end{array}$ & $\mathbf{M}$ & 56 & $\begin{array}{l}\text { fever } \\
\text { generalized status } \\
\text { with coma meningism } \\
\text { right hemiplegia }\end{array}$ & 50 & 400 & 500 & 100 & 22000 & $\begin{array}{l}\text { whole con } \\
\text { (fig 5) }\end{array}$ & 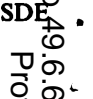 \\
\hline $\begin{array}{l}\text { Case } 6 \\
840544\end{array}$ & $\mathbf{M}$ & 15 & 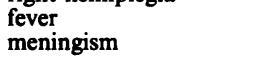 & 80 & 300 & 500 & 15 & 6000 & $\begin{array}{l}\text { FR SDE } \\
\text { (fig 6) }\end{array}$ & 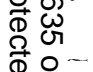 \\
\hline $\begin{array}{l}\text { Case } 7 \\
\quad 841050\end{array}$ & $\mathbf{F}$ & 24 & $\begin{array}{l}\text { fever } \\
\text { focal and generalised } \\
\text { seizures with coma } \\
\text { meningism aphasia }\end{array}$ & 100 & 1100 & 740 & 80 & 12000 & $\begin{array}{l}\text { IH SDE } \\
\text { TE SDE } \\
\text { (fig 7) }\end{array}$ & 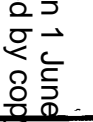 \\
\hline
\end{tabular}

M, male; F, female; P, proteins (mg/1); G, glucose (mg/1); SDE, subdural empyema; IH, interhemispheric; PA, parietal; FR, frontal; TE, temperal;

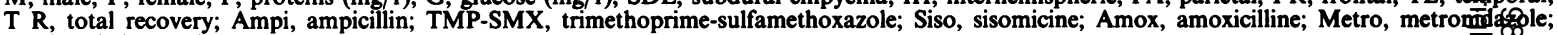
PRIS, pristinamycine.

after the introduction of penicillin. ${ }^{17}$ More recently, ampicillin and especially chloramphenicol have been preferred, because of their good diffusion into the central nervous system ${ }^{1318}$ and their effectiveness on anaerobic organisms, which are frequently isolated from subdural empyemas. ${ }^{18}$
Why have we tried a non-surgical treatment?

Surgery has usually been performed as an emergency because of two objections to a non-surgical treatment: firstly, antibiotics do not penetrate into loculated intracranial suppurations, and secondly, it is necessary to know the causative organism and its sensibility to
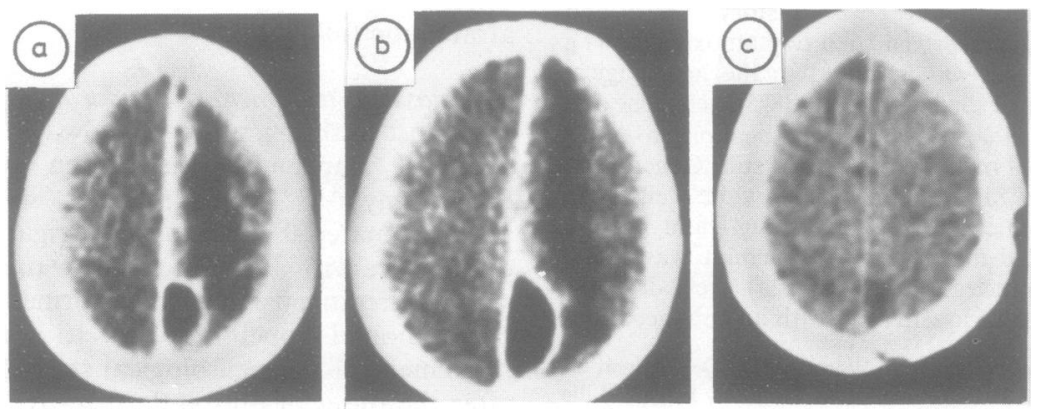

Fig 1 (Patient 1) (a) On admission: interhemispheric and left parietal subdural empyema. (b) After a 30 day course of antibiotics: disappearance of the most part of the empyema, but increase of the posterior part. (c) A year later: no residual empyema. 


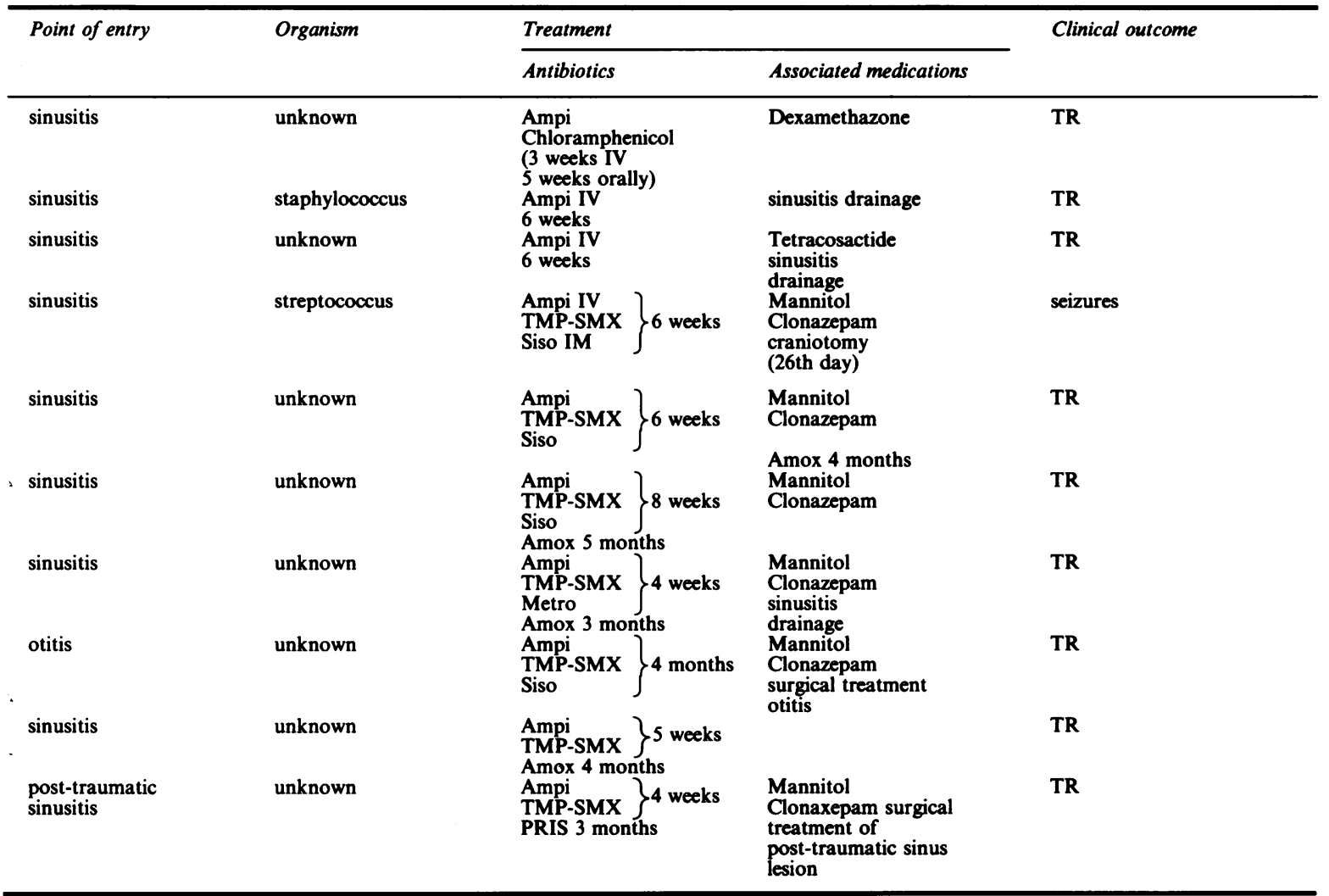

antibiotics. To our knowledge, antibiotic has never been found in the pus of subdural empyemas, as it has in brain abscesses; ${ }^{19}$ nevertheless, in our cases 2 to 7 , antibiotics were sufficient to improve the patients' state and to normalise the CT scan. In two of Rosazza's cases ${ }^{13}$ and in Rousseaux' case, ${ }^{20}$ antibiotics had also been able to cure such lesions. Our first patient was surgically treated one month after the
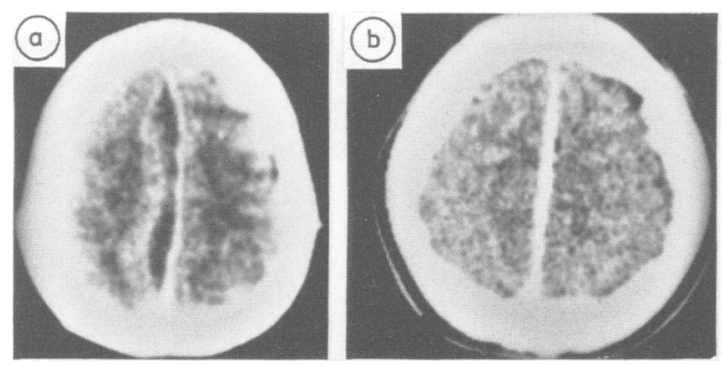

Fig 2 (Patient 2) (a) On admission: interhemispheric subdural empyema. (b) During the 6th month: CT scan is normal. onset of the antibiotherapy: his neurological condition had improved, but surgery was decided because the size of the most posterior part of the empyema had gradually increased; this patient was our first medically treated patient but now, with Rosazza and Rousseaux' experiences, ${ }^{1320}$ and from our next six patients, we think that it would have been possible to treat him without surgery. In Kaufman ${ }^{121}$ and
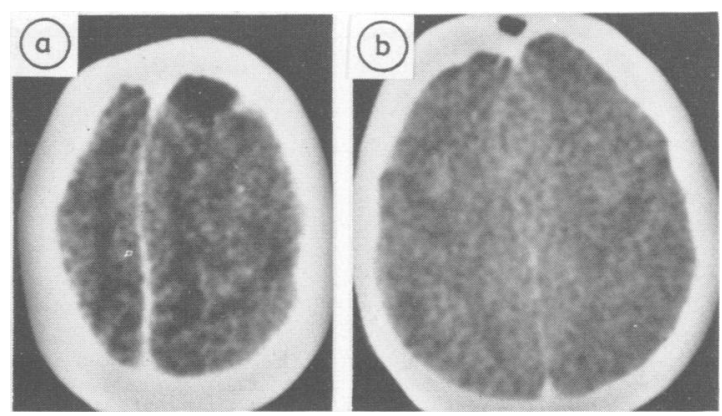

Fig 3 (Patient 3) (a) On admission: frontal subdural empyema. (b) Eight months later: no residual empyema. 


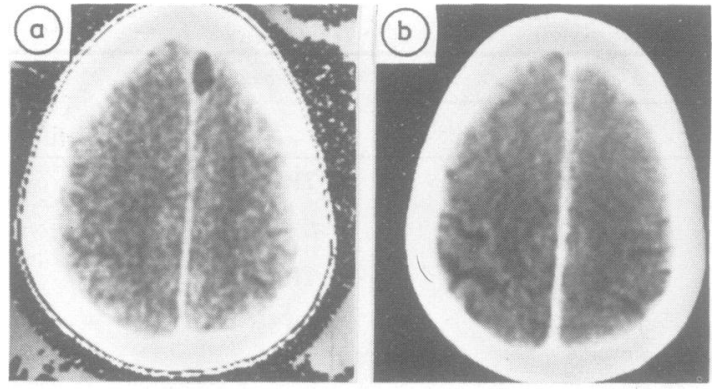

Fig 4 (Patient 4) (a) On admission: interhemispheric subdural empyema. (b) Four months later: no residual empyema.

Holtzman ${ }^{122}$ cases, the neurological condition deteriorated in spite of antibiotics. We are not sure whether the dosage was sufficient, but, in our cases, although the patients often showed a little deterioration during the first 24 or 48 hours, we always continued the same treatment. So, we think that antibiotics are probably able to penetrate into subdural empyemas. The pus has been free of organisms in our patient 1 and reported by Borzone et al. ${ }^{23}$ This penetration is perhaps made possible by an unusual development of meningeal arteries, as in our third case, which brought large quantities of antibiotics in the margin of the empyema. ${ }^{2425}$

It is not always necessary to know the causative organism from the empyema itself. In our seven cases, the causative organism was found only in the first patient, from blood cultures. Surgery is not indicated for identification of the organism as in brain abscesses; this is possible in less than $50 \%$ of the operated cases, and in $30 \%$ of the non-surgically treated ones, from blood or CSF cultures, or from the point of entry; moreover, the organism is, in most cases, sensitive to large spectrum antibiotics used intravenously with high doses.

\section{Modalities of the medical treatment}

We have used intravenous antibiotic therapy for 4 to
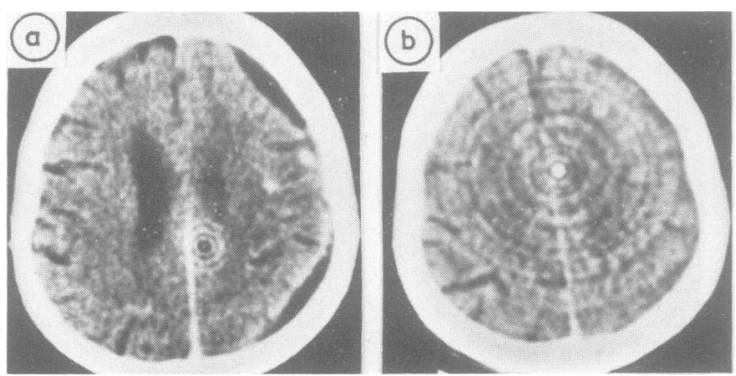

Fig 5 (Patient 5) (a) On admission: subdural empyema of the whole convexity. (b) One year later: CT scan is normal.
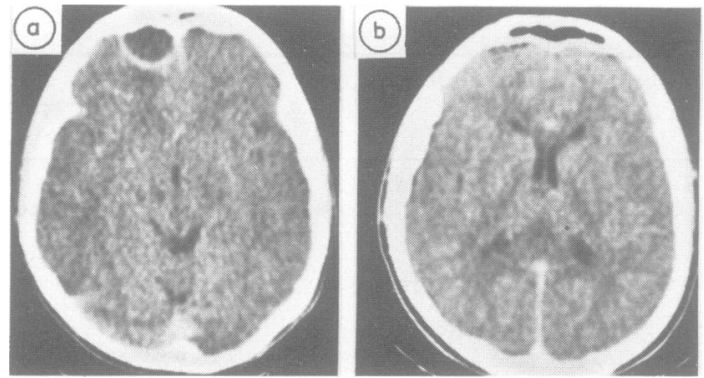

Fig 6 (Patient 6) (a) On admission: right frontal subdural empyema. (b) Four months later: no residual empyema.

6 weeks and oral antibiotics until the CT scan was normal in all cases except the first in which the patient himself stopped the treatment in the sixth week. We think it is possible to stop earlier, as in Rosazza' cases, ${ }^{13}$ but care is required to ensure sterilisation of these lesions. Clonazepam was used when generalised seizures occurred. Corticosteroids have been avoided during the acute phase as they prevent antibiotics from penetrating into the abscesses. ${ }^{8}$ To prevent oedema, $10 \%$ hypertonic mannitol was used during the first few days. Of course, surgical treatment might have been necessary for patients who were rapidly deteriorating neurologically with medical treatment. However, in our second and seventh cases, a little deterioration did not lead to surgery. In four cases, antibiotics alone were sufficient to treat the initial infection of paranasal sinuses; in one case, delayed surgery prevented relapse and in two cases, early surgery was necessary to treat the paranasal sinusitis.

\section{Results}

With classical treatment, associating emergency surgery and antibiotics, the mortality was high $^{12326-28}$ and sequelae (focal deficits or epileptic seizures) were frequent. ${ }^{15}$ In our cases, only one patient had sequelae, (generalised seizures) and he had

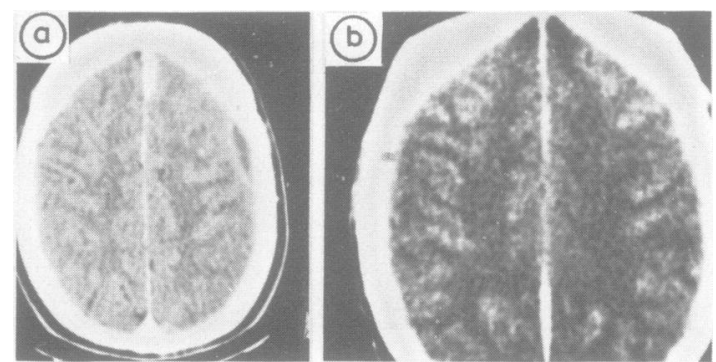

Fig 7 (Patient 7) (a) On admission: interhemispheric and temporal subdural empyema. (b) Six months later: no residual empyema. 
been operated upon. After 6 to 30 months, the other six have no focal deficit or seizure. The three other patients previously reported ${ }^{1320}$ in the literature, also have had no sequelae.

For these 10 cases, summarised in the table, the morbidity and mortality obtained by medical treatment alone seem better than those by surgical treatment, ${ }^{28}$ as also shown in brain abscesses. ${ }^{10}$ Many studies have shown that the most important prognostic factor in intracranial infection is the level of consciousness when the treatment is commenced. Three patients (cases $2,4,6$ ) were not in coma and they may therefore have been expected to have a better prognosis, no matter how they were treated. Nevertheless, the four others were in coma, and three had total recovery, and one little sequelae. In the literature, with surgery, the mortality and morbidity seem higher. ${ }^{28}$

A long period of intravenous treatment may be a financial disadvantage as compared with perhaps a more rapid response to surgical drainage, leading to earlier discharge and cheaper overall treatment; nevertheless, shorter treatments are possible, as in our first patient, and it would be possible to discharge these patients earlier in the future, when our experience will be greater. Moreover, less sequelae is also a financial advantage.

The authors thank Mr François Leung for the revision of the English manuscript.

\section{References}

${ }^{1}$ Bannister G, Williams B, Smith S. Treatment of subdural empyema. J Neurosurg 1981;55:82-8.

${ }^{2}$ Hadj-Djilana M, Calliauw L. A contribution to the Rapid Diagnosis of Subdural Empyema. Acta Neurochir (Wein) 1982;61:187-99.

${ }^{3}$ Stern J, Bernstein CA, Whelan MA, Neu HC. Pasteurella multocida subdural empyema: Case Report. $J$ Neurosurg 1981;54:550-2.

${ }^{4}$ Kaufman DM, Miller MH, Steigbigel NH. Subdural empyema: analysis of 17 recent cases and review of the literature. Medicine 1975;54:485-98.

${ }^{5}$ Cowie R, Williams B. Late seizures and morbidity after subdural empyema. $J$ Neurosurg 1983;58:569-73.

${ }^{6}$ Petit H, Rousseaux M, Lesoin F, Destée A, Clarisse J, Warot P. Primauté du traitement médical des abcès cérébraux (19 cas). Rev Neurol (Paris) 1983; 139:575-81.

${ }^{7}$ Leys D, Lesoin F, Viaud C, et al. Decreased morbidity from acute bacterial spinal epidural abscesses using computed tomography and non surgical treatment in selected patients. Ann Neurol 1985;17:350-5.

${ }^{8}$ George B, Roux F, Pillon M, Thurel C, George C. Relevance of antibiotics in the treatment of brain abscesses. Report of a case with eight simultaneous brain abscesses treated and cured medically. Acta Neurochir (Wein)
1979;47:285-91.

${ }^{9}$ Petit H, Destée A, Leys D, Warot P. Volumineux abcès listérien du tronc cérébral. Effet favorable de l'antibiothérapie. Rev Neurol (Paris) 1983;139:149-54.

${ }^{10}$ Rousseaux M, Lesoin F, Destée A, Jomin M, Petit H. Long term sequelae of hemispheric abscesses as function of the treatment. Acta Neurochir (Wein). (in press).

${ }^{11}$ Leys $D$, Destée $A$, Warot $P$. Empyème extradural en fosse postérieure. Traitement médical exclusif. Presse Med 1983;12:1549.

${ }^{12}$ Leys D, Destée A, Combelles G, Rousseaux M, Warot P. Les empyèmes sous-duraux intracrâniens. Trois observations. Sem Hop (Paris) 1983;59:3347-50.

${ }^{13}$ Rosazza A, De Triboulet N, Deonna TH. Non surgical treatment of interhemispheric subdural empyemas. Helv Paed Acta 1979;34:577-81.

${ }^{14}$ Pimontel-Appel B, Bochner A, Ghevens J, Klaes R, Bross J, Ebinger G. Subdural empyema: improvement of the emergency diagnosis by use of computed tomography (CT). Two personal cases study. J Belge Radiol 1980;63:109-17.

${ }^{15}$ Le Beau J, Creissard P, Harispe L, Recondo A. Surgical treatment of brain abscess and subdural empyema. $J$ Neurosurg 1973;38:198-203.

${ }^{16}$ Smith HP, Hendrick EB. Subdural empyema and epidural abscess in children. $J$ Neurosurg 1983;58:392-7.

${ }^{17}$ Schiller F, Cairns H, Russel DS. The treatment of purulent pachymeningitis and subdural suppuration with special reference to penicillin. $J$ Neurol Neurosurg Psychiatry 1948;11:143-82.

${ }^{18}$ Yoshikawa TT, Chow AW, Guze LB. Role of anaerobic bacteria in subdural empyema. Report of four cases and review of 327 cases from the English literature. Am J Med 1975;58:99-104.

${ }^{19}$ Black P, Graybill JR, Charache P. Penetration of brain abscess by systemically administered antibiotics. $J$ Neurosurg 1973;38:705-9.

${ }^{20}$ Rousseaux M, Lesoin F, Jomin M. Traitement médical d'un empyème sous-dural parasagittal. Presse Med 1984;13:2153.

${ }^{21}$ Kaufman DM, Litman N, Miller MH. Sinusitis induced subdural empyema. Neurology (Cleveland) 1983; 33:123-32.

${ }^{22}$ Holtzman RNN, Tepperberg J, Schwartz O. Parasagittal subdural empyema: a case report with computerized tomographic scan documentation. Mount Sinaï J Med 1980;47:62-7.

${ }^{23}$ Borzone M, Capuzzo T, Rivano C, Tortori-Donati P. Subdural empyema: fourteen cases surgically treated. Surg Neurol 1980;13:449-52.

${ }^{24}$ Handa J, Hanakita J, Koyama T, Handa H. Interhemispheric subdural empyema with an enlarged tentorial artery and vein. Neuroradiology 1976;9:167-70.

${ }^{25} \mathrm{Kim}$ KS, Weinberg PE, Magidson M. Angiographic features of subdural empyema. Radiology 1976;118:621-5.

${ }^{26}$ Bhandari YS, Sarkari NBS. Subdural empyema. A review of 37 cases. J Neurosurg 1970;32:35-9.

${ }^{27}$ Weinman D, Samarasinghe HHR. Subdural empyema. Aust NZ J Surg 1972;41:324-30.

${ }^{28}$ Williams B. Subdural empyema. In: Krayenbühl H, ed. Advances and Technical Standards in Neurosurgery, Vol 9. New York: Springer-Verlag, 1983:133-70. 